\title{
Composition and molecular scale structure of nanophases formed by precipitation of biotite weathering products
}

\author{
TAMRAT Wuhib Zewde1 ${ }^{1}$, Jérôme ROSE ${ }^{1}$, Olivier GRAUBY2 ${ }^{2}$ Emmanuel DOELSCH ${ }^{3}$,
} Clément LEVARD ${ }^{1}$, Perrine CHAURAND ${ }^{1}$, Isabelle BASILE-DOELSCH ${ }^{*}$

1- Aix-Marseille Université, CNRS, IRD, CEREGE UM34, USC INRA, 13545 Aix en Provence, France.

2- Aix-Marseille Université - UMR 7325 CINaM/CNRS, campus de Luminy, 13288 Marseille Cedex 9, France

\section{3- CIRAD, UPR Recyclage et risque, F-34398 Montpellier, France}

*Corresponding author: basile@cerege.fr

\section{Abstract}

Because of their large surface area and reactivity, nanometric-size soil mineral phases have a high potential for soil organic matter stabilization, contaminant sorption or soil aggregation. In the literature, $\mathrm{Fe}$ and $\mathrm{Al}$ phases have been the main targets of batchsynthesized nanomineral studies while nano-aluminosilicates ( $\mathrm{Al}$ and Si phases) have been mainly studied in Andic soils. In the present work, we synthesized secondary nanophases of $\mathrm{Fe}, \mathrm{Al}$ and $\mathrm{Si}$. To simulate a system as close as possible to soil conditions, we conducted laboratory simulations of the processes of (1) biotite alteration in acidic conditions producing a $\mathrm{Al} \mathrm{Si} \mathrm{Fe} \mathrm{Mg} \mathrm{K}$ leachate solution and (2) the following neoformation of secondary nanophases by titrating the leachate solution to $\mathrm{pH} 4.2,5$ and 7. The morphology of the nanophases, their size, crystallinity and chemistry were characterized by TEM-EDX on single particles and their local atomic structure by EXAFS (Extended X-ray Absorption Fine Structure) at the Fe absorption K-edge. The main nanophases formed were amorphous particles 10 to $60 \mathrm{~nm}$ in size whose composition (dominated by $\mathrm{Fe}$ and $\mathrm{Si}$ ) was strongly controlled by the $\mathrm{pH}$ conditions at the end of the titration. At pH 4.2 and $\mathrm{pH} \mathrm{7,} \mathrm{the} \mathrm{structure} \mathrm{of} \mathrm{the} \mathrm{nanophases} \mathrm{was} \mathrm{dominated} \mathrm{by} \mathrm{the}$ polymerization of $\mathrm{Fe}$, which was hindered by $\mathrm{Al}, \mathrm{Si}, \mathrm{Mg}$ and $\mathrm{K}$. Conversely, at $\mathrm{pH} \mathrm{5}$, the polymerization of Fe was counteracted by precipitation of high amounts of Si. The synthetized nanophases were estimated to be rather analogous to nanophases formed in natural biotite-bearing soils. Because of their small size and potential high surface 
reactivity, the adsorption capacities of these nanophases with respect to the OM should be revisited in the framework of soil C storage.

\section{Introduction}

Because of their large surface area, large percentage of surface atoms with unbalanced charge and large number of surface functional groups per unit of mass, nanometric-size mineral phases have a high potential for soil organic matter stabilization (Levard et al., 2012; Qafoku, 2010), contaminant adsorption, (Levard et al., 2009) or soil aggregation (Asano and Wagai, 2014) . These natural nanoparticles (NPs) may occur either as «mineral NPs » (defined as minerals that can also exist in larger sizes) or as «nanominerals» (defined as minerals that only exist at the nanometric scale) (Hochella et al., 2008).

In surface environments, $\mathrm{Fe}$ and $\mathrm{Al}$ systems have been the main subjects of previous studies due to soil observations (Kaiser and Guggenberger, 2000) as well as due to the poor solubility of $\mathrm{Fe}$ and $\mathrm{Al}$ species in most soil $\mathrm{pH}$ and redox conditions ( $\mathrm{pH}$ above $\approx 2$ for $\mathrm{Fe}$ in oxidative conditions and $\mathrm{pH}$ above $\approx 5$ for $\mathrm{Al}$ ). However nanominerals other than $\mathrm{Al}$ and Fe oxy-hydroxides are known to form in surface systems, one of the best known examples being the Al and Si imogolite/allophane phases (Basile-Doelsch et al., 2007; Basile-Doelsch et al., 2005; Basile-Doelsch et al., 2015; de Junet et al., 2013; Torn et al., 1997).

Released by the continuous alteration of the primary minerals, $\mathrm{Al}, \mathrm{Si}, \mathrm{Fe}$, etc. can form nanominerals at the surface of the primary mineral or at a distance from the initial altered surfaces. Direct formation of nanophases by the weathering of rock material has been described in oxic waters (Faimon, 2003; Zänker et al., 2006). In presence of organic matter, these newly formed nanophases can complex the organic compounds and stabilize them for extended periods of time. The conceptual model proposed by BasileDoelsch et al. (2015) represents this mechanism. To validate the model, it is necessary to show that (1) the products of the alteration of primary minerals are likely to form nanophases and (2) these nanophases complex the OM. In this paper, we focus on step (1). We characterized the chemical nature and the structure of the nanophases formed from the elements resulting from the alteration of a primary mineral in the absence of OM. For this purpose, we considered biotite as a common soil primary mineral able to 
63

64

65

66

67

68

69

70

71

72

73

74

75

76

77

78

79

80

81

82

83

84

85

86

87

88

89

90

91

92

provide a complex combination of elements ( $\mathrm{Fe}, \mathrm{Al}, \mathrm{Si}, \mathrm{Mg}$ and $\mathrm{K}$ ) via weathering.

The formation of nanophases from a solution requires a polymerizing step by hydrolysis of metallic cations like Fe or Al (Doelsch et al., 2000; Manceau and Drits, 1993; Rose et al., 1997). In oxic conditions and at $\mathrm{pH}$ higher than $3-4, \mathrm{Fe}^{3+}$ for instance, is known to be insoluble and reactive. (Byrne et al., 2000; Dousma and Debruyn, 1976;

Rose and Waite, 2003). Polymerization steps start from elementary monomeric building blocks such as $\left[\mathrm{Fe}\left(\mathrm{H}_{2} \mathrm{O}\right)_{6}\right]^{3+}$ octahedron and are accomplished via intramolecular condensation that initially involves deprotonation (Combes et al., 1989; Rose et al., 1997). Formation of small clusters via edge and double corner sharing between Fe octahedra is all included in the initial stage of "nucleation" which is followed by later stages of growth and aggregation (Rose et al., 1997; Wells, 1984). Polymerization routes have also been found for $\mathrm{Al}$, with the formation of a transient $\mathrm{Al}_{13}$ polymer (Bottero et al., 1980). It has been shown that Si can strongly impair the polymerization stages in both elements (Doelsch et al., 2000; Lartiges et al., 1997).

Our experimental protocol combined a weathering step that provided a complex solution of $\mathrm{Fe}, \mathrm{Si}, \mathrm{Al}, \mathrm{K}$ and $\mathrm{Mg}$ cations, followed by the polymerization of nanophases in a range of $\mathrm{pH}$ corresponding to soil conditions ( $\mathrm{pH} 4.2,5$ and 7). The atomic structures of the nanophases were determined by Fe k-edge EXAFS (Extended X-ray Absorption Fine Structure) spectroscopy and size, shape, crystallinity and chemical composition by TEM-EDX. Three main questions are raised in this paper: (1) Does the proposed experimental protocol make it possible to obtain nanophases? (2) Are the polymerized nanophases homogeneous or of variable chemical composition? (3) Are the nanophases obtained representative of phases that can form in soils?

\section{Materials and Methods}

\subsection{Experimental protocol}

The biotite studied comes from Bancroft, Ontario Canada (Ward Science) (Turpault and Trotignon (1994)):

$$
K_{0.92}\left(F e_{1.06}^{(2+)} M g_{1.66}\right)\left(F e_{0.094}^{(3+)} \mathrm{Ti}_{0.12} \mathrm{Mn}_{0.046}\right)\left[\mathrm{Si}_{3} \mathrm{AlO}_{10}\right]\left(\mathrm{OH}_{1.1} \mathrm{~F}_{0.9}\right)
$$

Biotite was mechanically ground $(<50 \mu \mathrm{m})$ in a zirconium oxide 'ball mill' setup, washed, sieved with ultra pure water and dried at $40^{\circ} \mathrm{C}$. 
Dissolution step: $33 \mathrm{~g}$ of $<50 \mu \mathrm{m}$ biotite particles were placed in $1 \mathrm{~L}$ of $\mathrm{pH}=2 \mathrm{HNO}_{3}$ solution (solid:liquid ratio of 1:30). After 29 days, the dissolved species were separated from non-weathered biotite particles using Tangential Filtration flow (TFF) (Spectrum Labs) at a cut-off size of $10 \mathrm{kD}$ (pore size of $\sim 2 \mathrm{~nm}$ ). The filtered solution is hereafter referred to as 'leachate solution'. Concentrations of dissolved species in the leachate solution were monitored with an inductively coupled plasma atomic emission spectrophotometer (ICP-AES, Horiba Jobin-Yvon "Ultima C", Longjumeau, France). The measurement uncertainty was $<10 \%$. The preliminary experimental setup that contributed to the design of the above dissolution protocol is detailed in supplementary information (Figure A1 and Table A1).

Polymerization step: Nanophases were precipitated by increasing the $\mathrm{pH}$ of the leachate solution. The initial $\mathrm{pH}(2)$ was raised by adding $0.2 \mathrm{~N} \mathrm{NaOH}$ (Sigma Aldrich) at a constant rate of $70 \mu \mathrm{L} / \mathrm{min}$ (785 DMP Titrino). Pyrex beakers and stir bars were used. Three final $\mathrm{pH}$ values were targeted: $4.2,5$ and 7 . To determine the target $\mathrm{pH}$ values, a preliminary titration curve of the leachate solution was performed (Figure A2). The slope of this curve changed at $\mathrm{pH} 4.2$ and 5 . The variations in slope pointed to changes in the nature of the hydrolyzing system, inferring correlative changes in the nature and/or structure of the polymerized phases. At $\mathrm{pH} 7$, the addition of $\mathrm{NaOH}$ no longer had an effect on polymerisation. The durations of titration were 1.4, 1.5 and 1.67 hours at $\mathrm{pH}$ 4.2, 5 and 7 respectively. When the target $\mathrm{pH}$ was reached, a $1 \mathrm{ml}$ aliquot of sample was collected for TEM-EDX analyses and the remaining solution was ultra-centrifuged at 80 $000 \mathrm{rpm}$ for $2 \mathrm{~h}$ to separate precipitated nanophases from the dissolved species. The settled particles were freeze-dried for EXAFS analyses. The whole experimental protocol is summarized in Figure A3.

\subsection{TEM images and analyses}

Images were obtained and chemical analyses of nanophases were performed using a transmission electron microscope coupled with an EDX analyzer (JEOL JEM 2011 TEM). For each sample, EDX analyses were performed on a set of around 40 nanophases of different sizes. The parameters were $50000 \mathrm{X}$ magnification, an angular tilt of $20^{\circ}$ toward the detector, energy range of $40 \mathrm{keV}$, and corrected counting time of $30 \mathrm{~s}$. A constant beam density was set at $\sim 63.5{\mathrm{pA} . \mathrm{cm}^{-2}}^{-2} \mathrm{Fe}, \mathrm{Si}, \mathrm{Al}, \mathrm{K}$, and $\mathrm{Mg}$ were quantified 
124 using the Bruker AXS MET line mark data quantification procedure (Berthonneau et al., 125 2014). The size of each EDX-analyzed nanoparticle was subsequently measured on the 126 corresponding micrograph.

\subsection{EXAFS at the Fe $\mathrm{K}$ edge}

Extended X-ray absorption fine structure (EXAFS) spectroscopy at the Fe K-edge data was performed at the ESRF synchrotron source on the FAME beam line (Grenoble, France) and on beam line 11.1 at the ELETTRA synchrotron (Trieste, Italy). Spectra were acquired using $\mathrm{Si}(220)$ and $\mathrm{Si}(111)$ double crystal monochromators at the ESRF and ELETTRA for the samples and the references respectively. Spectra were acquired at ambient conditions in both transmission and fluorescence modes (30-element solidstate Ge detector (Canberra, France)). All the samples were pressed into $5 \mathrm{~mm}$ diameter pellets mixed with boron nitride as a dilution agent. Each spectrum comprised an average of 3 to 5 individual spectra taken $107 \mathrm{eV}$ below and $849 \mathrm{eV}\left(14.75 \AA^{-1}\right)$ above the absorption edge of Fe (7112 eV) at a counting rate of 2-9 seconds until $14.75 \AA^{-1}$. To get representative spectra and minimize the risk of beam damage, each spectrum was collected at a different pellet location. Data were treated using Athena software (Ravel and Newville, 2005). All radial distances in the RDF (Radial Distribution Function) were not corrected for phase shift (Figure 3b). According to the relation $\Delta R=\pi / 2 \mathrm{k}$, the minimum distance resolution of $0.11 \AA$ was achieved.

A two-stage approach was used for the quantitative analysis of EXAFS data. The first stage consisted of using linear combination fitting (LCF) based on EXAFS spectral library of reference compounds. The second stage consisted of shell by shell fitting (SSF) to investigate the atomic environment of Fe. The two quantitative methods were performed at all three $\mathrm{pH}$. The results of the two methods were in agreement. Only the SSF method is described in the paper because this method provided additional information on the local structure. Details of the LCF are presented in supplementary information.

Goethite, Ferrihydrite, Fe short range order (Fe-SRO) phase and Fe dimers were used as references. Goethite provides the highest Fe polymerization level of all reference compounds with $4 \mathrm{Fe}-\mathrm{Fe}$ octahedra edge-sharing and 4 double corner-sharing interactions. Ferrihydrite is characterized by fewer edge interactions (2 to 2.5) and double corner interactions ( 3-5) than goethite (Maillot et al., 2011; Michel et al., 2007). 
156 Fe-SRO is composed of Fe polymers formed in Si rich solutions. Fe polymers are 157 characterized by 2 edge-sharing but only a 0.6 double corner interaction. Fe polymers 158 were synthesized at $\mathrm{pH} 5$ in presence of $\mathrm{Si}(\mathrm{Si} / \mathrm{Fe}=4)$, conditions in which there are no 159 Si-O-Fe interactions (Doelsch et al., 2000; Doelsch et al., 2001). For Fe dimers only 1 160 edge-sharing coordination has been described (Rose et al., 1996)). (See Supplementary 161 Information for details on reference samples).

162 Shell by shell fitting (SSF) was used to extract structural information such as the 163 coordination number $\left(\mathrm{N}_{\mathrm{j}}\right)$ and interatomic distances $\left(\mathrm{R}_{\mathrm{j}}\right)$ relative to the absorber atom 164 using the software code Artemis (Ravel and Newville, 2005). The contributions of the 165 different atomic shells were assessed using back-Fourier transform of the pseudo-radial 166 distribution function. These partial EXAFS functions were then least-squares fitted by a 167 theoretical function (in the single-scattering approximation) in order to determine the structural and chemical parameters of the atomic neighbors in the atomic shells around Fe. Uncertainties for radial distances remained within a conservative $\pm 0.02 \AA$ range typical in the determination of this parameter (Pokrovski et al., 2002). Varying the $\mathrm{k}$ weight magnified or eliminated different sections of the EXAFS signal. A k weight of 3 was used for SSF techniques. To determine an appropriate value for E0 and amplitude reduction factor (So2), the lepidocrocite spectrum with pre-confirmed structural information was used to set those values to $2 \mathrm{eV}( \pm 2 \mathrm{eV})$ and 0.75 respectively. It is worth noting that in complex media, various fits of similar quality can be obtained. It is therefore important to recall that structural results are not necessarily univocal.

\section{Results}

3.1 Chemical composition of the leachate solution and conditions for the formation of nanophases

The chemical composition of the leachate solution is presented in Table 1. Fe, Mg and $\mathrm{Si}$ were the main contributors to the leachate solution, while $\mathrm{Al}$ and $\mathrm{K}$ contributed to a

182 lesser extent. $\mathrm{Mn}$ and Ti concentrations were negligible (Figure A1) and were not 183 included in the atomic proportions.

184 The preliminary titration experiment of the leachate solution (Figure A2) showed 185 that $\mathrm{pH} 4.2$, pH 5 and $\mathrm{pH} 7$ were the values at which changes in the polymerization 
186

187

188

189

190

191

192

193

194

195

196

197

198

199

200

201

202

203

204

205

206

207

208

209

210

211

212

213

214

215

regime could be expected. Theoretically, nanophases formed at these three different $\mathrm{pH}$ should thus reveal differences in chemical composition and/or atomic structure.

\subsection{TEM-EDX characterization of nanophases}

Polymerization experiments resulted in nanophases obtained at three final $\mathrm{pH} 4.2,5$ and 7. Collected masses of nanophases ranged between 11 to $15 \mathrm{mg}$. Regardless of the $\mathrm{pH}$, particles were aggregated, forming distinct clusters of small and large particles (Figure 1). The size distribution showed a bimodal Gaussian fit with maxima at $6( \pm 3.7)$ $\mathrm{nm}$ and $30( \pm 15) \mathrm{nm} . \sim 15 \mathrm{~nm}$ was the cut-off size between smaller and larger particles. Volume estimates showed that the volume of larger particles was 50 times larger than the volume of smaller particles. Electron diffraction analyses revealed a diffuse pattern across all pH and particle sizes (Figure 1).

Fe and Si mainly composed the nanophases regardless of the $\mathrm{pH}$ and size range (Figure $2 \mathrm{~A}$ and $\mathrm{B}$ ). The proportions of $\mathrm{Fe}$ and $\mathrm{Si}$ were higher than in the leachate solution, indicating preferential polymerization of Fe and Si compared with the other elements. The proportions of $\mathrm{Al}$ in the nanophases were close to those in the leachate solution. The contribution of $\mathrm{Al}$ was limited, even at $\mathrm{pH} \geq 5$ when polymerization of $\mathrm{Al}$ was theoretically expected. The proportions of $\mathrm{K}$ and $\mathrm{Mg}$ in the nanophases were in the same range as that of Al. However, they were significantly depleted in the nanophases compared to in the leachate solution. Finally, in terms of general trends as a function of $\mathrm{pH}, \mathrm{pH} 5$ represented a singular case in which the large particles were extremely $\mathrm{Si}$ enriched and $\mathrm{Fe}$ and $\mathrm{Al}$ depleted.

\subsection{EXAFS at the Fe K-edge: iron atomic range structure}

\subsubsection{Comparison of raw data}

The structural interactions between Fe octahedra are represented as signals at $\sim 5.2$ $\AA^{-1}$ and $\sim 7.5 \AA^{-1}$ on the EXAFS spectra (Figure 3a and Figure B1) (Mikutta, 2011; Mikutta et al., 2010; Pokrovski et al., 2003). These interactions were also observed as peaks in Rspace at radial distances of $\sim 2.7 \AA$ and $\sim 3.2 \AA$ corresponding to edge and double corner sharing interactions respectively (Figure 3b) (Rose et al., 1997). In transiting from the 'goethite and 2L ferrihydrite' to 'Fe-SRO and Fe dimers' references, i.e. with decreasing Fe octahedra polymerization, the weak intensity in k-space at $\sim 5.2 \AA^{-1}$ converted into a 
216 faint shoulder and the intensity of the $\sim 7.5 \AA^{-1}$ feature decreased. The above change in 217 crystalline order was also seen in R-space with the double corner peak at $\sim 3.2 \AA$ 218 disappearing and peak at $\sim 2.7 \AA$ decreasing in intensity. In the reference standards, the 219 locations of these Fe-Fe markers changes from a shoulder to a fully formed peak as the $220 \mathrm{Fe}$ polymerization increases from $\mathrm{Fe}$ dimers to Goethite. This increase in $\mathrm{Fe}$ 221 polymerization is accompanied by shift in location of the signals from lower to higher wavenumber values.

Features at $\sim 5.2 \AA^{-1}$ and $\sim 7.5 \AA^{-1}$ on the experimental EXAFS spectra showed that iron polymers larger than dimers were formed during the precipitation steps at each $\mathrm{pH}$ (Figure 3). Phases formed at the pH 4.2 produced a spectrum for the above-mentioned 226 Fe-Fe markers whose intensity was between that for goethite and 2L ferrihydrite. These 227 phases produced distinct structural signals with the highest intensity of all the samples 228 (Figure 3). For pH 5 and 7 phases, collective comparison of $\mathrm{k}$ and R-space spectra gave an average between 2L ferrihydrite and Fe-SRO references. The intensities of these two samples were weaker than that of the $\mathrm{pH} 4.2$ sample.

\subsubsection{Quantitative analysis of EXAFS data using shell by shell fitting}

In all samples, the first coordination sphere around iron was composed of oxygen atoms at a distance of $1.96 \pm 0.02 \AA$ (Table 2). The coordination number varied from 6.3$6.5 \pm 1.3$ for $\mathrm{pH} 4.2$ and $\mathrm{pH}$ 7. This result showed the formation of iron octahedra as the main iron species. However, at $\mathrm{pH} \mathrm{5,} \mathrm{the} \mathrm{coordination} \mathrm{number} \mathrm{was} \mathrm{significantly} \mathrm{lower}$

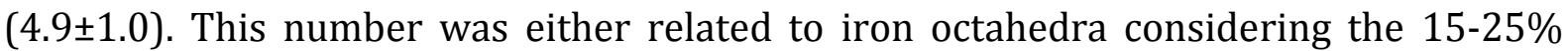
range error (2000; O'Day et al., 1994) or to the presence of a proportion of tetrahedral coordinated iron like in ferrihydrite due to a Keggin-like motif (Maillot et al., 2011; Michel et al., 2007).

The SSF of the second and third coordination spheres of all samples was performed by successively testing $\mathrm{Fe}-\mathrm{Fe}, \mathrm{Fe}-\mathrm{Si}$ and $\mathrm{Fe}-\mathrm{Al}$ atomic pairs. R-factors of all three atomic shell fits were systematically better than two atomic shell fits. Only three shell fits were

selected (Figure 4). Detailed steps in the SSF for all three phases are given in Figures C2.

244 For the $\mathrm{pH} 4.2$ sample, the best solution was obtained with Fe in the $2^{\text {nd }}$ atomic shell with $\mathrm{N}_{\mathrm{Fe} 2}=1.5 \pm 0.3$ at $\mathrm{R}_{\mathrm{Fe}-\mathrm{Fe} 2}=3.01 \pm 0.02 \AA$ and $\mathrm{Fe}$ in the $3^{\text {rd }}$ atomic shell with $\mathrm{N}_{\mathrm{Fe} 3}=1.9 \pm 0.4$ at a distance of $\mathrm{R}_{\mathrm{Fe}-\mathrm{Fe} 3}=3.38 \pm 0.02 \AA$. The interatomic distances were in agreement with

247 Fe-Fe octahedra edge and double corners sharing. The total Fe-Fe coordination number 
$248(\mathrm{~N}=3.4 \pm 20 \%)$ indicates a low level of polymerization (Table B1 and B2). For the pH 5

249 sample, two solutions had almost equal quality of fit (only differing in the path used for 250 the $3^{\text {rd }}$ atomic shell). The first solution used $\mathrm{Fe}^{-\mathrm{Fe}_{2}}$ edge sharing interaction at $251 \mathrm{R}=3.01 \pm 0.02 \AA$ with $\mathrm{N}_{\mathrm{Fe} 2}=1.1 \pm 0.2$ and $\mathrm{Fe}-\mathrm{Si}$ (or $\mathrm{Al}$ ) path at $\mathrm{R}=3.18 \pm 0.02 \AA$ with $252 \mathrm{~N}_{\mathrm{Si}}=3.9 \pm 0.8$. The Fe-Si $(\mathrm{Al})$ distance corresponded to a single corner sharing between the 253 Fe octahedron and the $\mathrm{Si}$ (or $\mathrm{Al}$ ) tetrahedron. The second solution only used Fe-Fe 254 octahedra edge sharing with $\mathrm{Fe}_{-} \mathrm{Fe}_{2}$ at $\mathrm{R}=2.99 \pm 0.02 \AA$ with $\mathrm{N}_{\mathrm{Fe} 2}=1.2 \pm 0.2$ and $\mathrm{Fe}-\mathrm{Fe}_{3}$ path at $\mathrm{R}=3.13 \pm 0.02 \AA$ with $\mathrm{N}_{\mathrm{Fe} 3}=0.6 \pm 0.1$. However, in both cases, the Fe-Fe coordination number (1.1-1.8 $\pm 20 \%)$ was much smaller than for the $\mathrm{pH} 4.2$ sample. For the $\mathrm{pH} 7$ sample, the best fits showed 3 solutions. The fit with the $\mathrm{Fe}-\mathrm{Fe}_{2}$ edge sharing path at $\mathrm{R}=3.07 \pm 0.02 \AA$ with $\mathrm{N}_{\mathrm{Fe} 2}=3.4 \pm 0.7$ and the $\mathrm{Fe}-\mathrm{Fe}_{3}$ double corner sharing path at $\mathrm{R}=3.36 \pm 0.02 \AA$ with $\mathrm{N}_{\mathrm{Fe} 3}=0.5 \pm 0.1$ could be the most reliable solution, according to the $\mathrm{Fe}$ dominant composition of the nanophases. Whatever the solution, at $\mathrm{pH} 7$, the total Fe-Fe coordination number $(2.5-3 \pm 20 \%)$ was higher than at $\mathrm{pH} 5$ but lower than at $\mathrm{pH} 4.2$.

\section{Discussion}

\subsection{Biotite dissolution rate and physical-chemical conditions of polymerization in} batches

The proportions of $\mathrm{Fe}, \mathrm{Si}, \mathrm{Al}, \mathrm{K}$ and $\mathrm{Mg}$ in the leachate solution (Table 1) differed from those in stoichiometry in biotite (Figure A1b). These proportions showed, as expected, that the dissolution of biotite is incongruent (Kalinowski and Schweda (1996); Turpault and Trotignon (1994); Bonneville, et al., 2009;Bonneville et al. (2011)). However, the calculated dissolution rates (Table A1) were slower than the values reported in the literature (see Bonneville et al. (2011) for a review). A $10 \mathrm{kD}$ filtration was applied in our protocol. This $\sim 2 \mathrm{~nm}$ cutoff allowed the truly dissolved components to be retreived separately from the undissolved colloidal particules (Buffle and van Leeuwen, 1992;

273 McCarthy and Zachara, 1989). By comparison, the most frequently used filtration protocols in other studies utilized filters with a cutoff size of $200 \mathrm{~nm}$ (Bonneville et al., 2011; Bray et al., 2015) to define the threshold for dissolved species. This difference may explain the observed slower dissolution rates in our experiments. We thus obtained a solution with elemental proportions that are representative of the weathering of a 
mineral (Table 1). This composition is therefore more representative of soil solutions than solutions produced by commercial metal salts as well as solutions that consider only $\mathrm{Fe}$ and $\mathrm{Al}$ ions in the formation of nanophases (Kleber et al. (2015) and references therein).

As revealed by TEM, the polymerization step enabled the formation of nanophases at $\mathrm{pH} 4.2,5$ and 7. These values correspond to realistic $\mathrm{pH}$ values in soils (Schwertmann and Murad, 1983; Yong and Phadungchewit, 1993). Moreover, experimental polymerization involves rapid changes in $\mathrm{pH}$. Such abrupt variations have also been observed at very small spatial scales (Bonneville et al., 2011) on biotite surfaces. Consequently, the batch approach used in our protocol, although greatly simplified compared to a soil system, made it possible to reproduce physical-chemical conditions that realistically mimic soil processes.

\subsection{Local structure of nanophases}

\subsubsection{The presence of $\mathrm{Al}, \mathrm{Si}, \mathrm{Mg}$ and $\mathrm{K}$ in the system limits Fe polymerization}

The coordination number (Ntot) is a direct proxy for the degree of polymerization. The levels of polymerization of the nanophases synthesized in our experiments were less than 3.4 whatever the pH (Figure 5). This value is lower than the number of Fe-Fe bonds in polymers synthesized in pure Fe systems (Combes et al., 1990; Combes et al., 1989; Doelsch et al., 2000). The same difference in values was also observed in systems in which Fe is hydrolyzed in presence of Si (Doelsch et al., 2003; Doelsch et al., 2000; Doelsch et al., 2002; Doelsch et al., 2001; Pokrovski et al., 2003). In our case, the presence of $\mathrm{Al}, \mathrm{Si}, \mathrm{Mg}$ and $\mathrm{K}$ in the solution clearly hinders the polymerization of $\mathrm{Fe}$ regardless of $\mathrm{pH}$.

\subsubsection{The $\mathrm{pH}$ controls the local structure of nanophases}

At $\mathrm{pH} 4.2$, the level of polymerization of the nanophases was the highest of our experiments (Figure 5) and Fe was the main element in the nanophases (Figure 2). FeFe bonds with double corner interactions dominated the local structure. The number of edge interactions was lower than double corners interactions (Figure 5). These polymers are therefore structured in three dimensions, resembling the local structure of the polymers described in systems where Fe polymerizes in the presence of Si at a pH close to 3 (Doelsch et al., 2000; Pokrovski et al., 2003). The occurrence of Fe-O-Si bonds 
between Fe octahedra and Si-tetrahedra was not observed (Table 2), which is consistent with the Fourier transformed infrared (FTIR) results obtained in conditions similar to our systems ( $\mathrm{Si} / \mathrm{Fe}=1$, pH 3) (Doelsch et al., 2001).

At pH 7, Fe was still the main element (Figure 2) but its degree of polymerization was slightly lower than that at $\mathrm{pH} 4.2$. However, unlike $\mathrm{pH} 4.2$, the octahedra were mostly bounded by their edges (Figure 5), forming rather planar local structures. Again, the system we studied behaved in a quite similar way to the Fe polymerization systems in the presence of Si (Doelsch et al., 2000; Doelsch et al., 2001). Moreover, these authors showed by FTIR the existence of Fe-O-Si bonds at $\mathrm{pH} \mathrm{7,} \mathrm{in} \mathrm{agreement} \mathrm{with} \mathrm{the} \mathrm{third}$ layer of our quantification by SSF (Table 2).

At $\mathrm{pH} \mathrm{5}$, the level of polymerization of Fe was significantly lower than that of the structures observed at pH 4.2 and 7 (Figure 5). The number of edge interactions was slightly greater than the number of double corners. This local structure is therefore quite close to a mixture of dimers and trimers. Quantification by SSF suggests the potential presence of $\mathrm{Fe}$ in tetrahedral form in the local structure as observed by (Pokrovski et al., 2003), but without clearly demonstrating it. On the other hand, like at pH 7, SSF analysis (Table 2) suggests the existence of Si-O-Fe bonds that correspond to the FTIR results obtained at $\mathrm{pH} 5$ for $\mathrm{Si} / \mathrm{Fe}=1$ (Doelsch et al., 2001). Thus, unlike the nanophases formed at $\mathrm{pH} 4.2$ and 7, the composition of the nanophases formed at $\mathrm{pH} 5$ is largely dominated by $\mathrm{Si}$ (Figure 2). Fe is present only as dimers and trimers, probably isolated in an amorphous silica matrix. The polymerization of $\mathrm{Fe}$ at $\mathrm{pH} 5$ was thus counteracted by the polymerization of high amounts of amorphous Si. Thermodynamic and/or kinetic mechanisms that control the variations in the proportions of Fe and Si in the nanophases as a function of $\mathrm{pH}$ remain to be explained.

\subsection{Two stages of precipitation: growth and maturation}

The individual nanophases had two particle size ranges (Figure 1) regardless of the $\mathrm{pH}$ considered. The differences in chemical composition as a function of size are better illustrated in the $\mathrm{Fe}, \mathrm{Si}$ and $\mathrm{Al}$ ternary diagram in Figure 6. Regardless of $\mathrm{pH}$, the chemical composition of the smaller particles was close to that of the initial leachate solution, with a slight enrichment in Fe. Two hypotheses can be proposed to highlight the chemical heterogeneity as function of the particle size. First, since no time series experiments were conducted the two particle types could have been formed from 
341 different precursors or second, the difference may be due to a maturation/aging 342 mechanisms. In the case of the second hypothesis, the smallest particles could be the 343 first nanometric phases that polymerize during titration. They could derive from the 344 rapid growth of the initial nuclei. The chemical compositions of the larger particles 345 differed from those of the smaller particles at the same $\mathrm{pH}$. They were enriched in $\mathrm{Fe}$ at $346 \mathrm{pH} 4.2$ and $\mathrm{pH} \mathrm{7,} \mathrm{and} \mathrm{enriched} \mathrm{in} \mathrm{Si} \mathrm{at} \mathrm{pH} \mathrm{5.} \mathrm{The} \mathrm{difference} \mathrm{in} \mathrm{the} \mathrm{composition} \mathrm{of} \mathrm{the}$ 347 larger and smaller particles means that simple aggregation of the smaller particles cannot explain the formation of the larger particles. Instead, we propose that these particles could be formed after the titration step, when the $\mathrm{pH}$ is stable, by a stage of maturation. Maturation (e.g. Ostwald ripening (Voorhees, 1985)) is a stage of dissolution/precipitation: the most unstable small particles as a result of the large surface area can be dissolved and re-precipitation occurs on the surface of other growing particles. The composition and structure of the nanophases formed during the hypothesized stage of maturation appeared to be strongly controlled by the $\mathrm{pH}$ conditions.

The TEM results thus tend to indicate two polymerization steps in the formation of nanophases: we propose a first initial growth, and second maturation. It is important to note that data from EXAFS were unable to distinguish between the two stages of polymerization. EXAFS information is still an average signal over all particle size ranges within a given sample. However, the observed structural differences, in particular the contribution of Si to the structure of the particles at pH 5 (Table 2 and Figure 5) tends to show that the EXAFS signal of the polymerized phases was rather dominated by the structure of the larger particles.

\subsection{Synthetized nanophases are representative of nanophases formed in surface} environments

In order to test the representativeness of the products formed in our experiment as analogues to nanophases formed in surface environments, we compared the particles synthesized with two types of nanophases naturally formed: the altered layer formed at

369 the surface of biotite and the nanophases formed at a distance from the initial altered surfaces.

371 The study of Bonneville et al. (2011) is particularly relevant to compare our results 372 with a layer of biotite alteration, since these authors reproduced the chemical alteration 
processes at mineral-mycorrhiza interface, representing the hotspot of the weathering engine at work in soils. The composition of the nanophases formed in our $\mathrm{pH} 5$ experiments are reported in Figure 7 together with their results averaged over the 20 $\mathrm{nm}$ thick altered-biotite zone. The comparison shows very similar compositions between nanophases formed in batch at $\mathrm{pH} 5$ and the products of the surface layer alterated biotite. Moreover, these authors also measured pHs at the mineral-mycorrhiza interfaces, varying from values below 4.6 up to 5.8. The nanophases formed in our pH 5 experiments can therefore be considered to be formed under rather similar conditions.

Even though the chemical compositions of nanophases $\mathrm{pH} 5$ and biotite-altered layer seemed similar, comparison of local atomic structures was more complex. In an earlier study, Bonneville et al. (2009) identified the presence of vermiculite and ferrihydrite in the altered biotite layer. These observations were consistent with those of Murakami et al. (2003) who, using high resolution TEM, observed these gradual mineralogical transformations in addition to the presence of chlorite. On the other hand, other studies tended to show that the alteration layer formed on the mineral surface is amorphous. The mechanism proposed is no longer a gradual transformation associated with the preferential diffusion of selected ions, but a process of interfacial dissolutionreprecipitation (Hellmann et al., 2015; Hellmann et al., 2003; Hellmann et al., 2012). The results obtained by Kawano and Tomita (2001) on an altered natural bytownite, which showed alteration of the amorphous layer, also support the latter process. In the case of an amorphous surface alteration layer, the nanophases synthesized by our protocol could be good analogs of the surface processes of the minerals.

Concerning the second type of nanophases (neoformed nanophases in soils at a distance from the altered mineral surface), the nanophases in our study may also be analogs of natural secondary nanomineral phases. Only a few authors have studied the composition and local atomic structure of such nanophases. Dai et al. (2014) observed the formation of nanoparticle aggregates after experimental alteration of bentonite by bacteria. SEM-EDX analyses showed that the nanoparticle aggregates were composed of $\mathrm{Si}, \mathrm{Na}, \mathrm{Ca}, \mathrm{Mg}, \mathrm{Al}, \mathrm{Fe}, \mathrm{K}$. Wen et al. (2014) also extracted nanophases in a $<450 \mathrm{~nm}$ fraction that exhibited $\mathrm{Al}, \mathrm{Si}$ and Fe compositions and amorphous structures. These two studies demonstrate that not only $\mathrm{Al}$ and $\mathrm{Fe}$, as classically described in literature, but also other elements such as $\mathrm{Si}, \mathrm{Na}, \mathrm{K}, \mathrm{Mg}$, and $\mathrm{Ca}$ may be involved in the formation secondary nanophases in surface environments. It is therefore probable that the 
nanophases that were synthesized in the present work are, at least in the case of the larger particles, representative of some nanophases formed in soils, sediments or other surface environments.

\section{Conclusion}

This laboratory work simulated the successive processes of biotite alteration and the following neoformation of secondary phases from ions in solution. The nanophases formed were amorphous phases that polymerized in two steps: (1) the initial growth phase formed 2 to $15 \mathrm{~nm}$ particles whose chemical composition closely resembled that of the alteration solution; (2) the maturation phase then resulted in 15 to $60 \mathrm{~nm}$ particles whose compositions are strongly controlled by the $\mathrm{pH}$ conditions. At $\mathrm{pH} 4.2$ and $\mathrm{pH} \mathrm{7,} \mathrm{the} \mathrm{structure} \mathrm{of} \mathrm{the} \mathrm{nanophases} \mathrm{was} \mathrm{dominated} \mathrm{by} \mathrm{Fe} \mathrm{but} \mathrm{its} \mathrm{polymerization}$ was hindered by the presence of $\mathrm{Al}, \mathrm{Si}, \mathrm{Mg}$ and $\mathrm{K}$. Conversely, at $\mathrm{pH}$ 5, the polymerization of $\mathrm{Fe}$ was counteracted by the polymerization of high amounts of amorphous $\mathrm{Si}$. Surprisingly, $\mathrm{Al}$ appeared to play a minor role in polymerization, regardless of the $\mathrm{pH}$. However, thermodynamic and/or kinetic mechanisms that control the variations in the proportions of $\mathrm{Fe}$ and $\mathrm{Si}$ in the nanophases as a function of $\mathrm{pH}$ remain to be explained. In comparison with previous alteration studies, the laboratory-synthetized phases of our study were estimated to be analogs of the nanophases formed in natural biotite-bearing soils at varying distances from biotite surfaces.

These nanophases have a high potential for contaminant sorption, aggregation processes as well as for organic matter stabilization in soils. In the framework of the $\mathrm{C}$ budget issues and the 4 per 1000 initiative, it would be interesting to examine the role and the mechanisms of the interactions between these $\mathrm{Fe}, \mathrm{Si}, \mathrm{Al}, \mathrm{Mg}$, $\mathrm{K}$ nanophases and soil organic matter. Like for the $\mathrm{Fe}$ or $\mathrm{Al}$ phases reported in the literature, one could expect coprecipitation processes leading to-medium to long term stabilization of $\mathrm{C}$ in soils.

\section{Acknowledgements}

This work was supported by Aix-Marseille University doctoral school ED251, ANR (NanoSoilC ANR-16-CE01-0012-02 project) and the Institut Universitaire de France. We would like to thank the European Synchrotron Radiation Facility (ESRF) (Grenoble, 
France) and ELETTRA synchrotron (Trieste, Italy) and their respective teams at the FAME and 11.1 beam lines for their kind and expert assistance during the EXAFS measurements. We thank Alain Plante who read the article and provided feedback.

\section{References}

Asano, M. and Wagai, R. (2014) Evidence of aggregate hierarchy at micro- to submicron scales in an allophanic Andisol. Geoderma 216, 62-74.

Basile-Doelsch, I., Amundson, R., Stone, W.E.E., Borschneck, D., Bottero, J.Y., Moustier, S., Masin, F. and Colin, F. (2007) Mineral control of carbon pools in a volcanic soil horizon. Geoderma 137, 477-489.

Basile-Doelsch, I., Amundson, R., Stone, W.E.E., Masiello, C.A., Bottero, J.Y., Colin, F., Masin, F., Borschneck, D. and Meunier, J.D. (2005) Mineralogical control of organic carbon dynamics in a volcanic ash soil on La Réunion. European Journal of Soil Science 56, 689-703.

Basile-Doelsch, I., Balesdent, J. and Rose, J. (2015) Are Interactions between Organic Compounds and Nanoscale Weathering Minerals the Key Drivers of Carbon Storage in Soils? Environ. Sci. Technol. 49, 3997-3998.

Berthonneau, J., Grauby, O., Ferrage, E., Vallet, J.-M., Bromblet, P., Dessandier, D., Chaudanson, D. and Baronnet, A. (2014) Impact of swelling clays on the spalling decay of building limestones: insights from X-ray diffraction profile modeling. European Journal of Mineralogy.

Bonneville, S., Morgan, D.J., Schmalenberger, A., Bray, A., Brown, A., Banwart, S.A. and Benning, L.G. (2011) Tree-mycorrhiza symbiosis accelerate mineral weathering: Evidences from nanometer-scale elemental fluxes at the hypha-mineral interface. Geochimica et Cosmochimica Acta 75, 6988-7005.

Bonneville, S., Smits, M.M., Brown, A., Harrington, J., Leake, J.R., Brydson, R. and Benning, L.G. (2009) Plant-driven fungal weathering: Early stages of mineral alteration at the nanometer scale. Geology 37, 615-618.

Bray, A.W., Oelkers, E.H., Bonneville, S., Wolff-Boenisch, D., Potts, N.J., Fones, G. and Benning, L.G. (2015) The effect of $\mathrm{pH}$, grain size, and organic ligands on biotite weathering rates. Geochimica et Cosmochimica Acta 164, 127-145.

Buffle, J. and van Leeuwen, H.P. (1992) Environmental particles.

Byrne, R.H., Luo, Y.R. and Young, R.W. (2000) Iron hydrolysis and solubility revisited: observations and comments on iron hydrolysis characterizations. Marine Chemistry 70, 23-35.

Combes, J.M., Manceau, A. and Calas, G. (1990) Formation of ferric oxides from aqueous solutions: a polyhedral approach by X-ray absorption spectroscopy. II. Hematite formation from ferric gels. Geochimica et Cosmochimica Acta 54, 1083-1091.

Combes, J.M., Manceau, A., G, C. and Bottero, J.Y. (1989) Formation of ferric oxides from aqueous solutions: A polyhedral approach by X-ray absorption spectroscopy: I. 
Hydrolysis and formation of ferric gels. Geochimica et Cosmochimica Acta 53, 583594.

Dai, Q., Zhao, Y., Dong, F., Wang, B. and Huang, Y. (2014) Interaction between bentonite and Bacillus litoralis strain SWU9. Applied Clay Science 100, 88-94.

de Junet, A., Basile-Doelsch, I., Borschneck, D., Masion, A., Legros, S., Marol, C., Balesdent, J., Templier, J. and Derenne, S. (2013) Characterisation of organic matter from organo-mineral complexes in an Andosol from Reunion Island. Journal of Analytical and Applied Pyrolysis 99, 92-100.

Dignac, M.-F., Derrien, D., Barré, P., Barot, S., Cécillon, L., Chenu, C., Chevallier, T., Freschet, G.T., Garnier, P., Guenet, B., Hedde, M., Klumpp, K., Lashermes, G., Maron, P.A., Nunan, N., Roumet, C. and Basile-Doelsch, I. (2017) Increasing soil carbon storage: mechanisms, effects of agricultural practices and proxies. A review. Agronomy for Sustainable Development 37, 14.

Doelsch, E., Masion, A., Rose, J., Stone, W.E.E., Bottero, J.Y. and Bertsch, P.M. (2003) Chemistry and structure of colloids obtained by hydrolysis of Fe(III) in the presence of SiO4 ligands. Colloids and Surfaces A: Physicochemical and Engineering Aspects $217,121-128$.

Doelsch, E., Rose, J., Masion, A., Bottero, J.Y., Nahon, D. and Bertsch, P.M. (2000) Speciation and Crystal Chemistry of Iron(III) Chloride Hydrolyzed in the Presence of SiO4 Ligands. 1. An Fe K-Edge EXAFS Study. Langmuir 16, 4726-4731.

Doelsch, E., Rose, J., Masion, A., Bottero, J.Y., Nahon, D. and Bertsch, P.M. (2002) Hydrolysis of Iron(II) Chloride under Anoxic Conditions and Influence of SiO4 Ligands. Langmuir 18, 4292-4299.

Doelsch, E., Stone, W.E.E., Petit, S., Masion, A., Rose, J., Bottero, J.-Y. and Nahon, D. (2001) Speciation and Crystal Chemistry of Fe(III) Chloride Hydrolyzed in the Presence of SiO4 Ligands. 2. Characterization of Si-Fe Aggregates by FTIR and 29Si Solid-State NMR. Langmuir 17, 1399-1405.

Dousma, J. and Debruyn, P. (1976) Hydrolysis-Precipitation Studies of Iron Solutions .1. Model for Hydrolysis and Precipitation from Fe(iii) Nitrate Solutions. Journal of Colloid and Interface Science 56, 527-539.

Eusterhues, K., Hädrich, A., Neidhardt, J., Küsel, K., Keller, T.F., Jandt, K.D. and Totsche, K.U. (2014) Reduction of ferrihydrite with adsorbed and coprecipitated organic matter: microbial reduction by Geobacter bremensis vs. abiotic reduction by Nadithionite. Biogeosciences 11, 4953-4966.

Faimon, J. (2003) Formation of Colloidal Silica and Alumina During Experimental Granodiorite Weathering. Aquatic Geochemistry 9, 305-341.

Hellmann, R., Cotte, S., Cadel, E., Malladi, S., Karlsson, L.S., Lozano-Perez, S., Cabié, M. and Seyeux, A. (2015) Nanometre-scale evidence for interfacial dissolutionreprecipitation control of silicate glass corrosion. Nat Mater 14, 307-311.

Hellmann, R., Penisson, J.-M., Hervig, R.L., Thomassin, J.-H. and Abrioux, M.-F. (2003) An EFTEM/HRTEM high-resolution study of the near surface of labradorite feldspar altered at acid pH: evidence for interfacial dissolution-reprecipitation. Physics and Chemistry of Minerals 30, 192-197. 
Hellmann, R., Wirth, R., Daval, D., Barnes, J.-P., Penisson, J.-M., Tisserand, D., Epicier, T., Florin, B. and Hervig, R.L. (2012) Unifying natural and laboratory chemical weathering with interfacial dissolution-reprecipitation: A study based on the nanometer-scale chemistry of fluid-silicate interfaces. Chemical Geology 294-295, 203-216.

Hochella, M.F., Lower, S.K., Maurice, P.A., Penn, R.L., Sahai, N., Sparks, D.L. and Twining, B.S. (2008) Nanominerals, Mineral Nanoparticles, and Earth Systems. Science 319, 1631-1635.

IPCC 2013 Climate Change 2013: The Physical Science Basis. Contribution of Working Group I to the Fifth Assessment Report of the Intergovernmental Panel on Climate Change. Cambridge University Press, , Cambridge, United Kingdom and New York, NY, USA,

Kaiser, K. and Guggenberger, G. (2000) The role of DOM sorption to mineral surfaces in the preservation of organic matter in soils. Organic Geochemistry 31, 711-725.

Kalinowski, B.E. and Schweda, P. (1996) Kinetics of muscovite, phlogopite, and biotite dissolution and alteration at $\mathrm{pH} 1-4$, room temperature. Geochimica et Cosmochimica Acta 60, 367-385.

Kawano, M. and Tomita, K. (2001) TEM-EDX study of weathered layers on the surface of volcanic glass, bytownite, and hypersthene in volcanic ash from Sakurajima volcano, Japan. American Mineralogist 86, 284-292.

Kleber, M., Eusterhues, K., Keiluweit, M., Mikutta, C., Mikutta, R. and Nico, P.S. (2015) Mineral-Organic Associations: Formation, Properties, and Relevance in Soil Environments, in: Donald, L.S. (Ed.), Advances in Agronomy. Academic Press, pp. 1140.

Kögel-Knabner, I., Guggenberger, G., Kleber, M., Kandeler, E., Kalbitz, K., Scheu, S., Eusterhues, K. and Leinweber, P. (2008) Organo-mineral associations in temperate soils: Integrating biology, mineralogy, and organic matter chemistry. Journal of Plant Nutrition and Soil Science 171, 61-82.

Lartiges, B.S., Bottero, J.Y., Derrendinger, L.S., Humbert, B., Tekely, P. and Suty, H. (1997) Flocculation of colloidal silica with hydrolyzed aluminum: An Al-27 solid state NMR investigation. Langmuir 13, 147-152.

Levard, C., Doelsch, E., Basile-Doelsch, I., Abidin, Z., Miche, H., Masion, A., Rose, J., Borschneck, D. and Bottero, J.Y. (2012) Structure and distribution of allophanes, imogolite and proto-imogolite in volcanic soils. Geoderma 183-184, 100-108.

Levard, C., Doelsch, E., Rose, J., Masion, A., Basile-Doelsch, I., Proux, O., Hazemann, J.-L., Borschneck, D. and Bottero, J.-Y. (2009) Role of natural nanoparticles on the speciation of $\mathrm{Ni}$ in andosols of la Reunion. Geochimica et Cosmochimica Acta 73, 4750-4760.

Maillot, F., Morin, G., Wang, Y., Bonnin, D., Ildefonse, P., Chaneac, C. and Calas, G. (2011) New insight into the structure of nanocrystalline ferrihydrite: EXAFS evidence for tetrahedrally coordinated iron(III). Geochimica et Cosmochimica Acta 75, 2708-2720.

Manceau, A. and Drits, V.A. (1993) Local structure of ferrihydrite and feroxyhite by EXAFS spectroscopy. Clay Minerals 28. 
McCarthy, J.E. and Zachara, J.M. (1989) Environmental Science \& Technology (ACS Publications). Environmental Science \& Technology 23, 496-502.

Michel, F.M., Ehm, L., Antao, S.M., Lee, P.L., Chupas, P.J., Liu, G., Strongin, D.R., Schoonen, M.A.A., Phillips, B.L. and Parise, J.B. (2007) The Structure of Ferrihydrite, a Nanocrystalline Material. Science 316, 1726-1729.

Mikutta, C. (2011) X-ray absorption spectroscopy study on the effect of hydroxybenzoic acids on the formation and structure of ferrihydrite. Geochimica et Cosmochimica Acta 75, 5122-5139.

Mikutta, C., Frommer, J., Voegelin, A., Kaegi, R. and Kretzschmar, R. (2010) Effect of citrate on the local Fe coordination in ferrihydrite, arsenate binding, and ternary arsenate complex formation. Geochimica et Cosmochimica Acta 74, 5574-5592.

Murakami, T., Utsunomiya, S., Yokoyama, T. and Kasama, T. (2003) Biotite dissolution processes and mechanisms in the laboratory and in nature: Early stage weathering environment and vermiculitization. American Mineralogist 88, 377-386.

O'Day, P.A., Newville, M., Neuhoff, P.S., Sahai, N. and Carroll, S.A. (2000) X-Ray Absorption Spectroscopy of Strontium(II) Coordination. J Colloid Interface Sci. 222, 184-197.

O'Day, P.A., Rehr, J.J., Zabinsky, S.I. and Brown, G.E., Jr. (1994) Extended X-ray Absorption Fine Structure (EXAFS) Analysis of Disorder and Multiple-Scattering in Complex Crystalline Solids. Journal of the American Chemical Society 116, 2938-2949.

Paustian, K., Lehmann, J., Ogle, S., Reay, D., Robertson, G.P. and Smith, P. (2016) Climatesmart soils. Nature 532, 49-57.

Pokrovski, G.S., Schott, J., Farges, F. and Hazemann, J.-L. (2003) Iron (III)-silica interactions in aqueous solution: insights from X-ray absorption fine structure spectroscopy. Geochimica et Cosmochimica Acta 67, 3559-3573.

Pokrovski, G.S., Schott, J., Hazemann, J.-L., Farges, F. and Pokrovsky, O.S. (2002) An X-ray absorption fine structure and nuclear magnetic resonance spectroscopy study of gallium-silica complexes in aqueous solution. Geochimica et Cosmochimica Acta 66, 4203-4222.

Qafoku, N.P. (2010) Terrestrial Nanoparticles and Their Controls on Soil-/Geo-Processes and Reactions. Advances in Agronomy 107, 33-91.

Ravel, B. and Newville, M. (2005) ATHENA, ARTEMIS, HEPHAESTUS: data analysis for Xray absorption spectroscopy using IFEFFIT. Journal of Synchrotron Radiation 12, 537-541.

Rose, A.L. and Waite, T.D. (2003) Kinetics of Hydrolysis and Precipitation of Ferric Iron in Seawater. Environmental Science \& Technology 37, 3897-3903.

Rose, J., Manceau, A., Bottero, J.-Y., Masion, A. and Garcia, F. (1996) Nucleation and Growth Mechanisms of Fe Oxyhydroxide in the Presence of PO4 Ions. 1. Fe K-Edge EXAFS Study. Langmuir 12, 6701-6707.

Rose, J., Manceau, A., Masion, A. and Bottero, J.-Y. (1997) Structure and Mechanisms of Formation of FeOOH(NO3) Oligomers in the Early Stages of Hydrolysis. Langmuir 13, 3240-3246. 
Schmidt, M.W.I., Torn, M.S., Abiven, S., Dittmar, T., Guggenberger, G., Janssens, I.A., Kleber, M., Kogel-Knabner, I., Lehmann, J., Manning, D.A.C., Nannipieri, P., Rasse, D.P., Weiner, S. and Trumbore, S.E. (2011) Persistence of soil organic matter as an ecosystem property. Nature 478, 49-56.

Schwertmann, U. and Murad, E. (1983) Effect of $\mathrm{pH}$ on the formation of goethite and hematite from ferrihydrite. Clays and Clay Minerals 31, 277-284.

Stockmann, U., Adams, M.A., Crawford, J.W., Field, D.J., Henakaarchchi, N., Jenkins, M., Minasny, B., McBratney, A.B., Courcelles, V.d.R.d., Singh, K., Wheeler, I., Abbott, L., Angers, D.A., Baldock, J., Bird, M., Brookes, P.C., Chenu, C., Jastrow, J.D., Lal, R., Lehmann, J., O’Donnell, A.G., Parton, W.J., Whitehead, D. and Zimmermann, M. (2013) The knowns, known unknowns and unknowns of sequestration of soil organic carbon. Agriculture, Ecosystems \& Environment 164, 80-99.

Torn, M.S., Trumbore, S.E., Chadwick, O.A., Vitousek, P.M. and Hendricks, D.M. (1997) Mineral control of soil organic carbon storage and turnover. Nature 389, 170-173.

Turpault, M.P. and Trotignon, L. (1994) The dissolution of biotite single crystals in dilute HNO3 at $24^{\circ} \mathrm{C}$ : Evidence of an anisotropic corrosion process of micas in acidic solutions. Geochimica et Cosmochimica Acta 58, 2761-2775.

Voorhees, P. (1985) The Theory of Ostwald Ripening. J. Stat. Phys. 38, 231-252.

Wells, A.F. (1984) Structural Inorganic Chemistry. Clarendon Press, New York.

Wen, Y., Li, H., Xiao, J., Wang, C., Shen, Q., Ran, W., He, X., Zhou, Q. and Yu, G. (2014) Insights into complexation of dissolved organic matter and Al(III) and nanominerals formation in soils under contrasting fertilizations using two-dimensional correlation spectroscopy and high resolution-transmission electron microscopy techniques. Chemosphere 111, 441-449.

Yong, R.N. and Phadungchewit, Y. (1993) pH influence on selectivity and retention of heavy metals in some clay soils. Canadian Geotechnical Journal 30, 821-833.

Zänker, H., Hüttig, G., Arnold, T. and Nitsche, H. (2006) Formation of iron-containing colloids by the weatheringof phyllite. Aquatic Geochemistry 12, 299. 


\section{Figure caption}

Figure 1: TEM micrographs of nanophases. For each pH, magnification increases from left to right. On 50 $\mathrm{nm}$ scale images, electronic diffraction is superimposed, revealing the amorphous structure of the nanophases. SP: smaller particles; LP: larger particles.

Figure 2: TEM-EDX chemical analysis of polymerized particles at three pH expressed in stoichiometric atomic \%. The box-and-whisker plots represent the median value, the upper and lower quartiles, as well as the min and max of the data. The chemical composition of the leachate solution (Leachate $S$.) is also shown for the sake of comparison (bold dashed line, with their respective element specific error values). A: chemical composition of the smaller nanophases; B: chemical composition of the larger nanophases. n: number of particles analyzed.

Figure 3: EXAFS (a) and RDF (b) plots. Arrows indicate locations of confirmed Fe-Fe signals. Spectra in black represent references. E and DC stand for edge-sharing and double corner sharing interactions respectively. Distances on the RDF are not corrected for phase shifts.

Figure 4: Shell-by-Shell fitting for samples $\mathrm{pH}=4.2, \mathrm{pH}=5$ and $\mathrm{pH}=7$. Fit numbers refer to Table 2.

Figure 5: Changes in the coordination numbers for all Fe-Fe atomic pairs in the SSF analysis (Table 2) with the lowest $\mathbf{R}$ factors, leading to minimum (min) and maximum values (max) for each type of interaction and for each $\mathrm{pH}$. Total represents the addition of coordination numbers by edge and double corner interactions. Total coordination numbers from pure Fe system from the literature are also shown for the sake of comparison.

Figure 6: Ternary diagrams of $\mathrm{Fe}, \mathrm{Si}$ and $\mathrm{Al}$ atomic proportions in the nanophases formed at $\mathrm{pH} 4.2,5$ and 7. The white star represents the initial composition of the leachate solution, the small black dots represent the composition of smaller nanophases and the larger grey dots the composition of larger nanophases.

Figure 7: Chemical compositions expressed as $\mathrm{K}: \mathrm{Si}, \mathrm{Mg}: \mathrm{Si}$, Fe:Si and $\mathrm{Al}: \mathrm{Si}$ ratios measured by TEM-EDX. Empty circles represent the chemical composition of the surface layer of an altered biotite (Bonneville et al., 2011) averaged over its $20 \mathrm{~nm}$ thickness. Black circles represent the mean composition of the larger particles formed in our pH 5 experiment. Error bars are standard deviations.

\section{Table Caption}

Table 1: Chemical composition of the leachate solution provided by the dissolution experiment.

Table 2: SSF analysis of $\mathrm{pH} 4.2,5$ and 7 phases. The $\mathrm{R}$ window is the radial distance range over which the fit is carried out. $N$, R and $\sigma$ represent the coordination number, radial distance and disorder, respectively. Eo is the starting energy value for the fit and R-factor is a parameter for fit quality. Fe-Fez corresponds to edge sharing, $\mathrm{Fe}_{\mathrm{Fe}}$ corresponds to double corner sharing. Fit numbers refer to the graph presented in Figure 4 and Figure $\mathrm{C1}$. 


\begin{tabular}{|c|c|c|c|c|c|c|c|c|c|c|c|c|c|}
\hline & $\begin{array}{c}\text { R window } \\
\AA \\
\AA\end{array}$ & $\begin{array}{c}\mathrm{N} \\
\pm 20 \% \\
\end{array}$ & $\begin{array}{l}R(\AA) \\
\pm 0.02 \\
\end{array}$ & $\sigma(\AA)$ & $\begin{array}{c}\mathrm{N} \\
\pm 20 \% \\
\end{array}$ & $\begin{array}{l}R(\AA) \\
\pm 0.02 \\
\end{array}$ & $\sigma(\AA)$ & $\begin{array}{c}\mathrm{N} \\
\pm 20 \% \\
\end{array}$ & $\begin{array}{l}R(\AA) \\
\pm 0.02 \\
\end{array}$ & $\sigma(\AA ̊)$ & $E_{o}(e V)$ & $\begin{array}{c}\mathrm{R}- \\
\text { factor }\end{array}$ & $\begin{array}{l}\text { Fit } \\
\text { No }\end{array}$ \\
\hline \multirow{6}{*}{$\mathrm{pH} 4.2$} & \multirow{6}{*}{$1.00-3.63$} & \multicolumn{3}{|c|}{ Fe-O } & \multicolumn{3}{|c|}{$\mathrm{Fe}-\mathrm{Si}$} & \multicolumn{3}{|c|}{$\mathrm{Fe}-\mathrm{Fe}_{3}$} & \multirow{2}{*}{0,0} & \multirow{2}{*}{0,128} & \multirow{2}{*}{2} \\
\hline & & 6.8 & 1.95 & 0.12 & 3.5 & 3.25 & 0.05 & 2.2 & 3.42 & 0.06 & & & \\
\hline & & \multicolumn{3}{|c|}{$\mathrm{Fe}-\mathrm{O}$} & \multicolumn{3}{|c|}{ Fe-Al } & \multicolumn{3}{|c|}{$\mathrm{Fe}-\mathrm{Fe}_{3}$} & \multirow{2}{*}{0.0} & \multirow{2}{*}{0.040} & \multirow{2}{*}{3} \\
\hline & & 6.6 & 1.94 & 0.12 & 3.5 & 3.02 & 0.04 & 1.6 & 3.40 & 0.03 & & & \\
\hline & & \multicolumn{3}{|c|}{$\mathrm{Fe}-\mathrm{O}$} & \multicolumn{3}{|c|}{$\mathrm{Fe}-\mathrm{Fe}_{2}$} & \multicolumn{3}{|c|}{$\mathrm{Fe}-\mathrm{Fe}_{3}$} & \multirow{2}{*}{4.0} & \multirow{2}{*}{0.023} & \multirow{2}{*}{4} \\
\hline & & 6.3 & 1.97 & 0.12 & 1.5 & 3.01 & 0.08 & 1.9 & 3.38 & 0.08 & & & \\
\hline \multirow{6}{*}{ pH 5} & \multirow{6}{*}{$1.00-3.09$} & \multicolumn{3}{|c|}{$\mathrm{Fe}-\mathrm{O}$} & \multicolumn{3}{|c|}{$\mathrm{Fe}-\mathrm{Fe}_{2}$} & \multicolumn{3}{|c|}{$\mathrm{Fe}-\mathrm{Fe}_{3}$} & \multirow{2}{*}{3.0} & \multirow{2}{*}{0.010} & \multirow{2}{*}{3} \\
\hline & & 4.7 & 1.96 & 0.09 & 1.2 & 2.99 & 0.07 & 0.6 & 3.13 & 0.05 & & & \\
\hline & & \multicolumn{3}{|c|}{ Fe-O } & \multicolumn{3}{|c|}{$\mathrm{Fe}-\mathrm{Fe}_{2}$} & \multicolumn{3}{|c|}{ Fe-Si } & \multirow{2}{*}{3.0} & \multirow{2}{*}{0.006} & 4 \\
\hline & & 4.9 & 1.96 & 0.09 & 1.1 & 3.01 & 0.09 & 3.9 & 3.18 & 0.09 & & & \\
\hline & & & $\mathrm{Fe}-\mathrm{O}$ & & & $\mathrm{Fe}-\mathrm{Fe}_{2}$ & & & Fe-Al & & 30 & 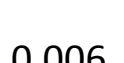 & 5 \\
\hline & & 4.9 & 1.96 & 0.09 & 1.0 & 3.00 & 0.08 & 4.9 & 3.21 & 0.08 & 3.0 & 0.000 & J \\
\hline & & & $\mathrm{Fe}-\mathrm{O}$ & & & $\mathrm{Fe}-\mathrm{Fe}_{2}$ & & & $\mathrm{Fe}^{-\mathrm{Fe}_{3}}$ & & 4.0 & 0.01 & 5 \\
\hline & & 6.5 & 1.98 & 0.11 & 2.5 & 3.06 & 0.11 & 0.5 & 3.35 & 0.11 & 4.0 & 0.011 & J \\
\hline $\mathrm{nH}_{7}$ & $100-21$ & & $\mathrm{Fe}-\mathrm{O}$ & & & $\mathrm{Fe}-\mathrm{Fe}_{2}$ & & & Fe-Al & & 40 & 0011 & 6 \\
\hline ד & $1.00-5.24$ & 6.5 & 1.98 & 0.11 & 2.5 & 3.06 & 0.11 & 2.1 & 3.45 & 0.08 & 4.0 & $0.01+$ & 0 \\
\hline & & & $\mathrm{Fe}-\mathrm{O}$ & & & $\mathrm{Fe}-\mathrm{Fe}_{2}$ & & & $\mathrm{Fe}-\mathrm{Si}$ & & 40 & 0.011 & 7 \\
\hline & & 6.5 & 1.98 & 0.11 & 2.6 & 3.06 & 0.11 & 1.6 & 3.42 & 0.08 & & $0.01+$ & $r$ \\
\hline
\end{tabular}



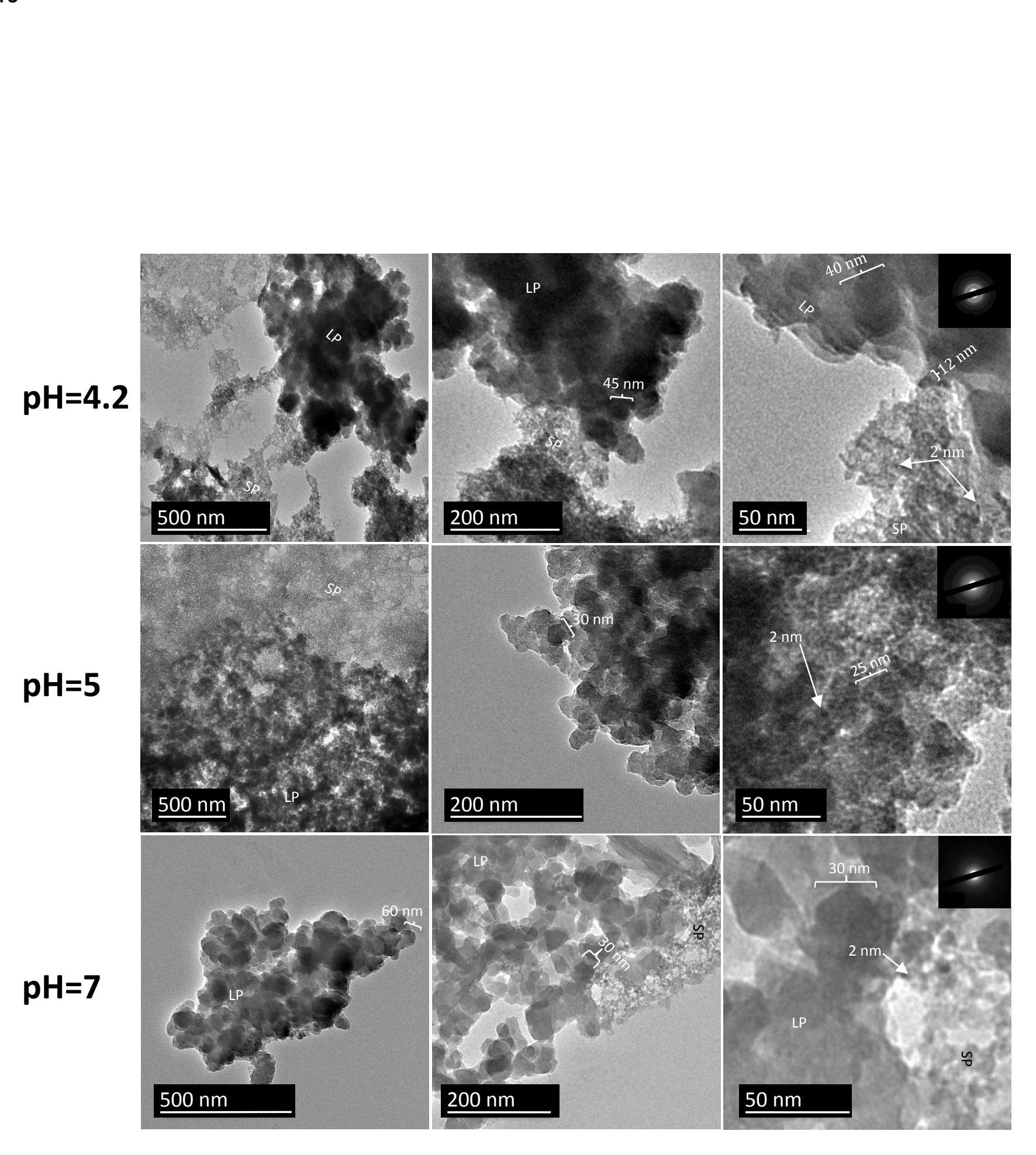

.

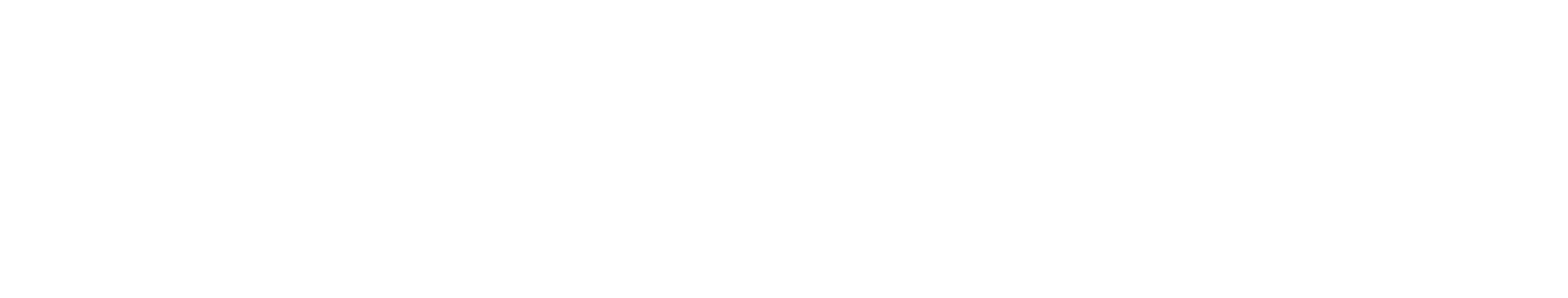
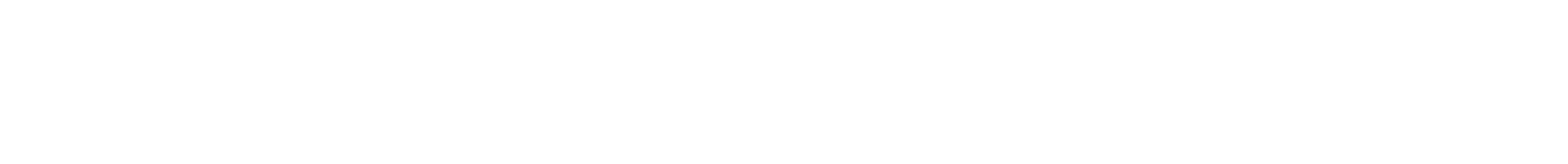

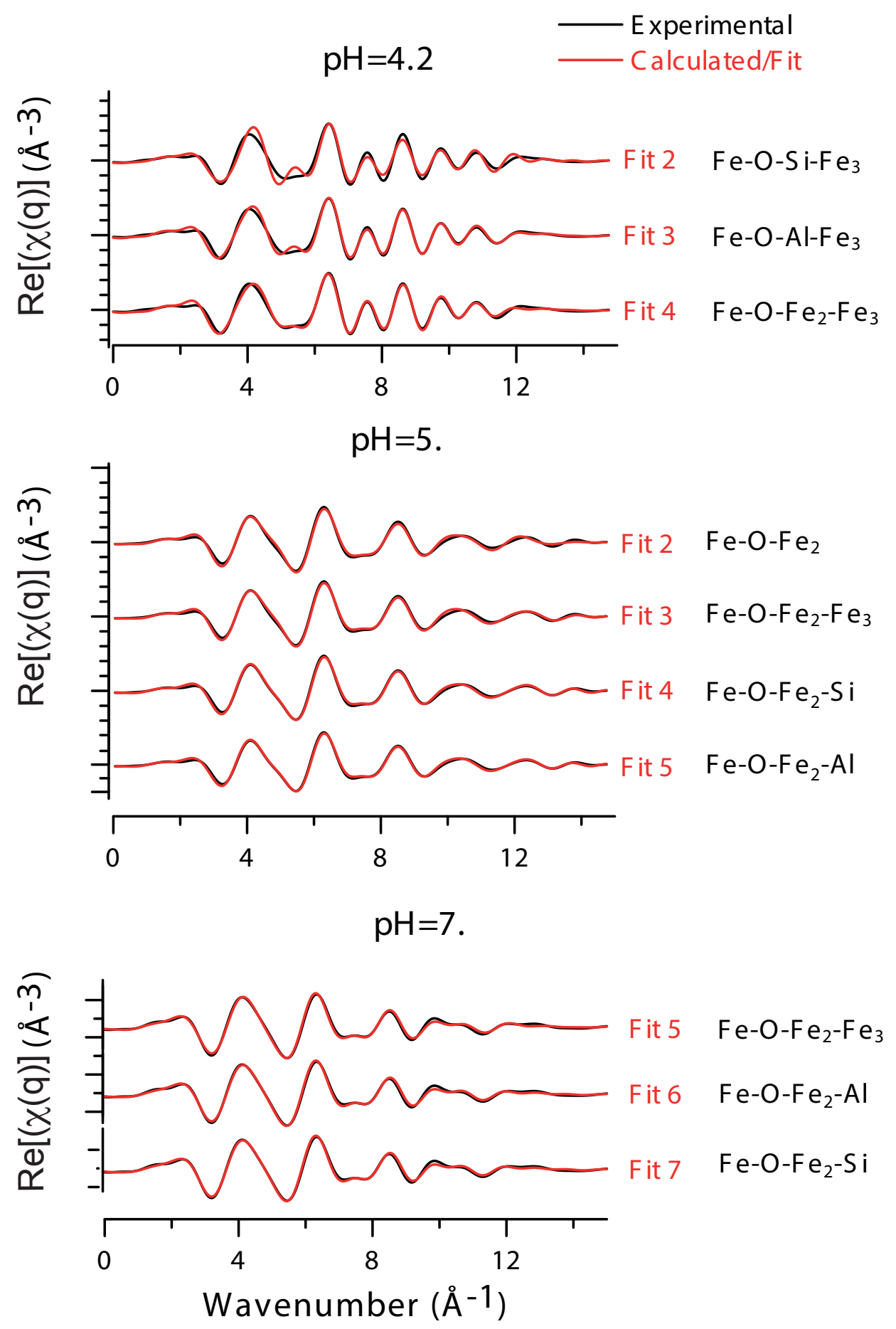


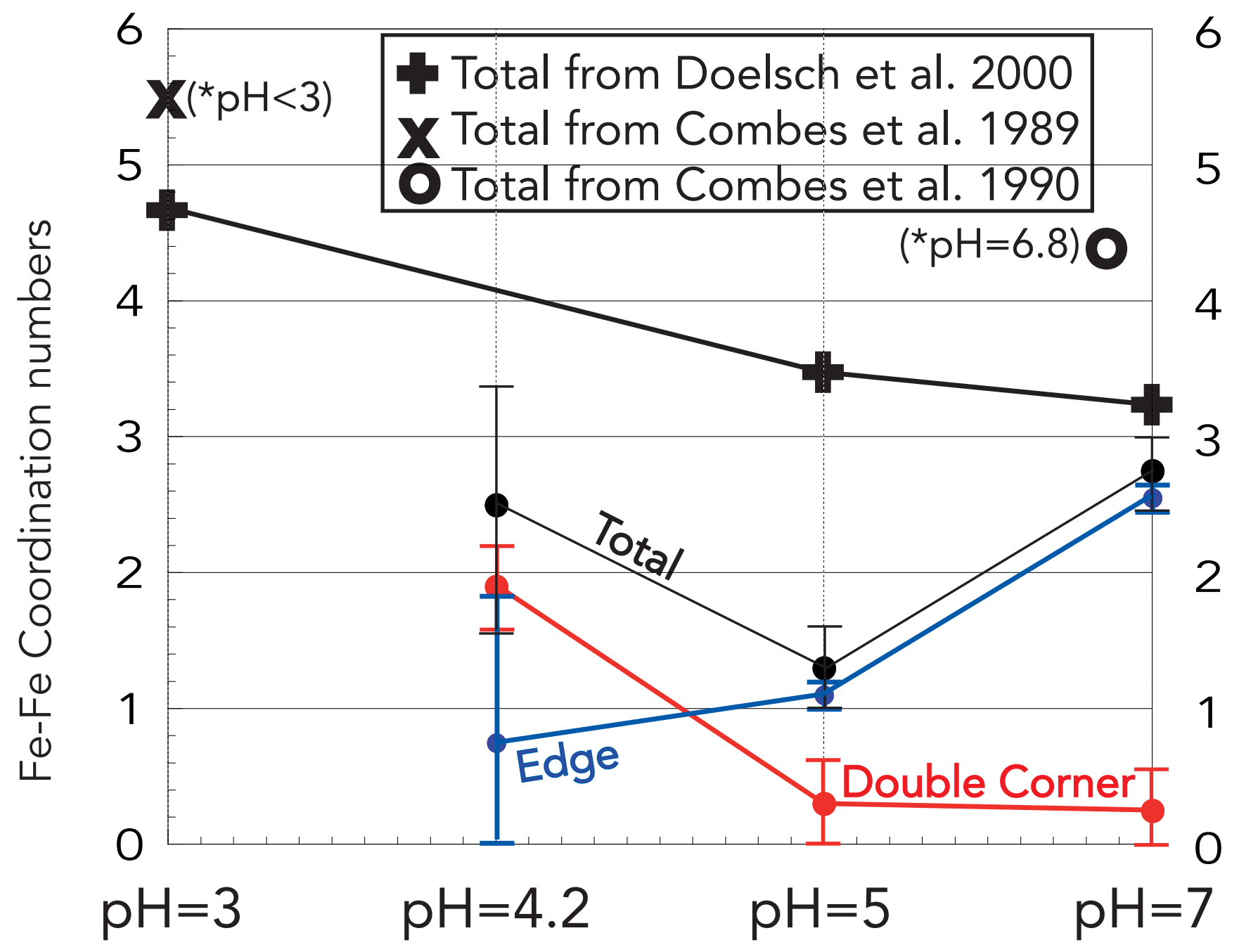




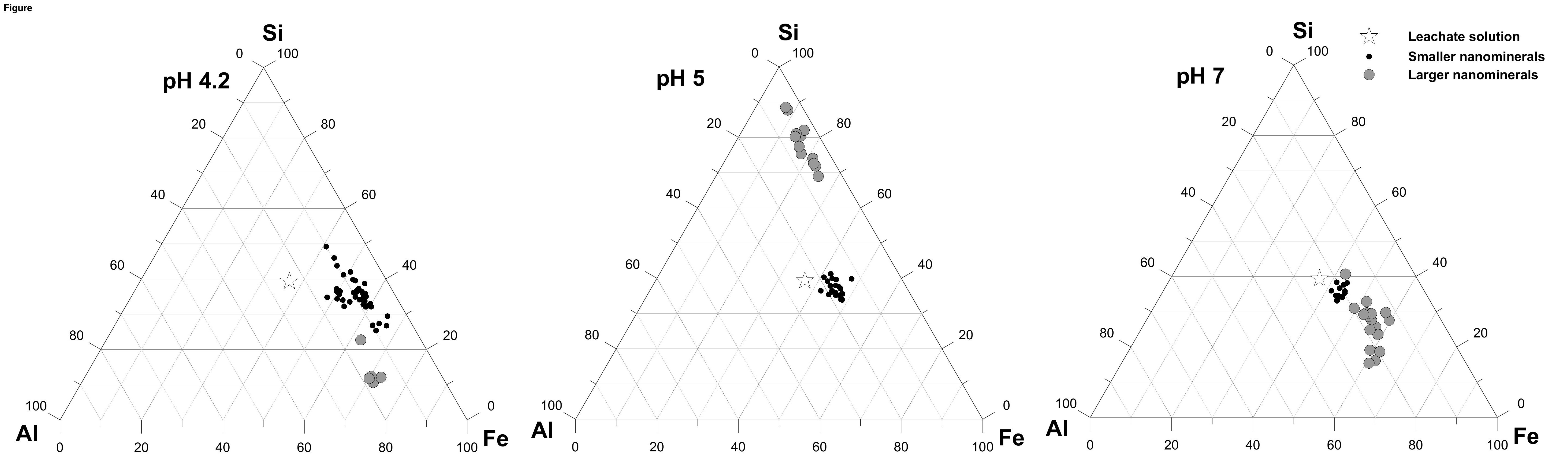


$20 \mathrm{~nm}$ layer of altered biotite (Bonneville et al., 2011)

- Larger nanominerals $\mathrm{pH} 5$ (this study)

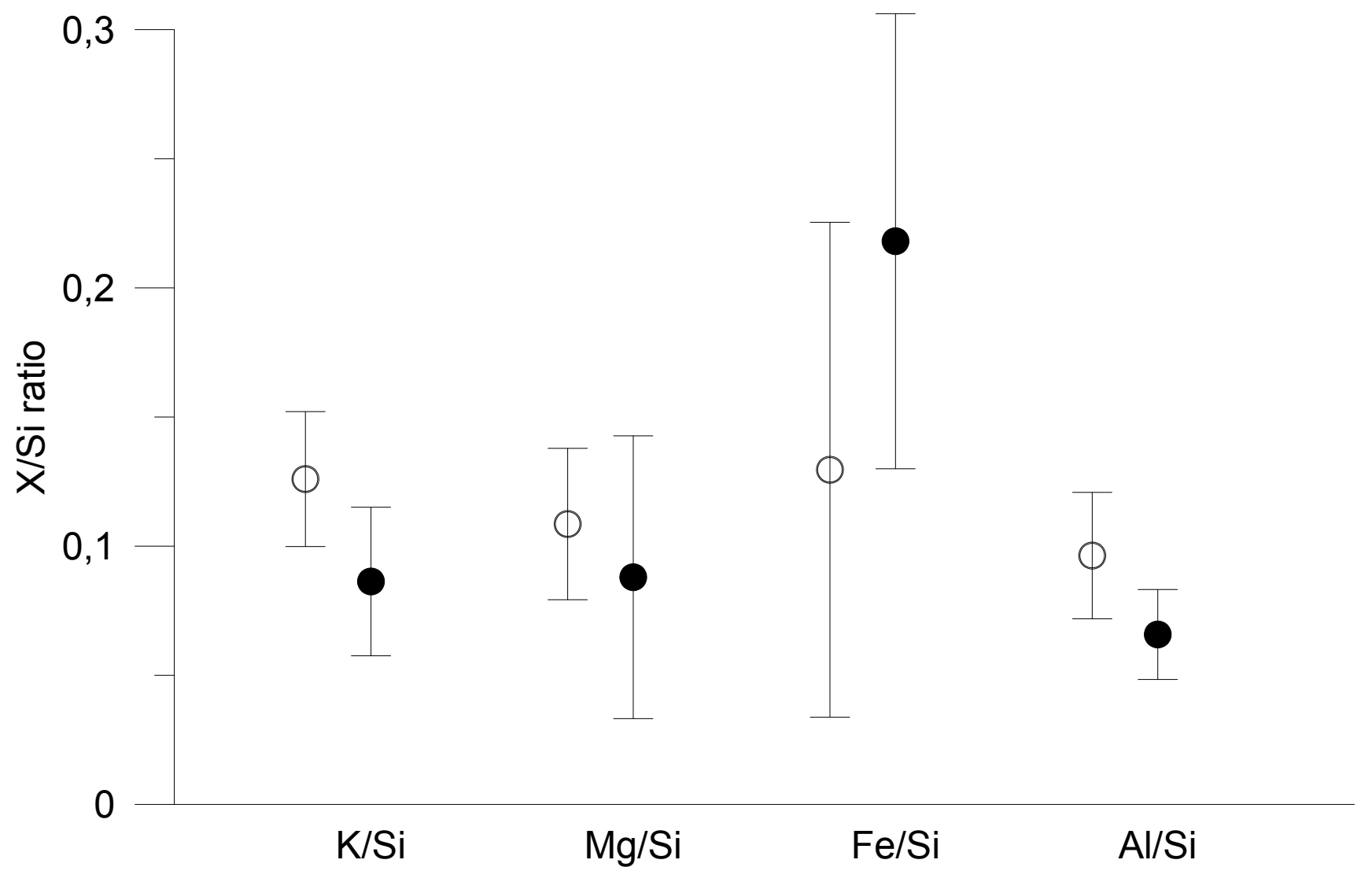


Appendix
Click here to download Appendix: TamratGCA_revised_4 with corrections.docx

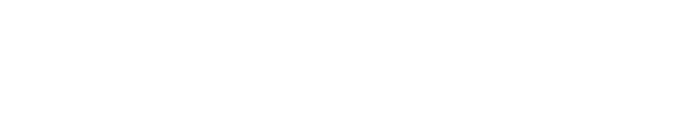
列

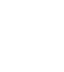

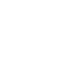

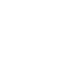
(1)

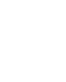

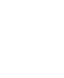

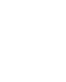

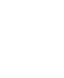

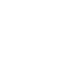
(1) (1)

Click here to download Appendix: TamratGcA_revised_4 with corrections.docx 
Electronic Annex
Click here to download Electronic Annex: Tamrat et al GCA Supp Inf revised V2.docx
( 